\title{
Recurrent Malignant Hypopharyngeal Neoplasm
}

National Cancer Institute

\section{Source}

National Cancer Institute. Recurrent Malignant Hypopharyngeal Neoplasm. NCI

Thesaurus. Code C9353.

The reemergence of a hypopharyngeal malignant neoplasm after a period of remission. 